\title{
ENVIRONMENT-BASED DESIGN (EBD) APPROACH TO IDENTIFY CRITICAL ISSUES IN MANAGING MUNICIPAL SOLID WASTE: NAIROBI, KENYAN CASE STUDY
}

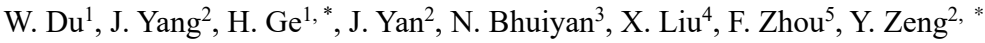 \\ ${ }^{1}$ Department of Building, Civil, and Environmental Engineering, Concordia University, Montreal, Quebec, Canada - \\ wenhang.du@mail.concordia.ca, hua.ge@concordia.ca \\ ${ }^{2}$ Concordia Institute for Information Systems Engineering, Concordia University, Montreal, Quebec, Canada - (jiami.yang, \\ jun.yan, yong.zeng)@ concordia.ca \\ ${ }^{3}$ Department of Mechanical and Industrial Engineering, Concordia University, Montreal, Quebec, Canada - \\ nadia.bhuiyan@concordia.ca \\ ${ }^{4}$ Department of China Institute for Urban Governance, Shanghai Jiaotong University, Shanghai, China - x_liu@ sjtu.edu.cn \\ ${ }^{5}$ Edmonton Power Corporation, Edmonton, Alberta, Canada - fzhou@epcor.com
}

KEYWORDS: Municipal solid waste management (MSWM), critical issues, Environment-based design (EBD), Environment-based life cycle analysis (eLCA), Nairobi

\begin{abstract}
:
As the urban population grows and the global economy develops, municipal solid waste management (MSWM) has become an increasingly prominent global issue. MSWM is particularly difficult in developing countries due to its high cost and time-consuming nature. The Environment-based design (EBD) can potentially contribute to global MSWM by reducing costs and increasing efficiency, especially in helping developing countries identify critical issues in MSWM. This paper uses and demonstrates the effectiveness and efficiency of the EBD method to analyze and identify critical issues in MSWM, using the city of Nairobi as a case study. This paper contains the first two of EBD's three activities: environment analysis and conflict identification, during the design problem period, design knowledge, and design solutions simultaneously and interdependently evolve as a part of the environment. The comparison with the existing literature confirms that the conclusions reached are, to some extent, reliable, time-saving, and less costly, which will offer a possibility to solve the problem of MSWM in impoverished areas.
\end{abstract}

\section{INTRODUCTION}

\subsection{Current Situation and Challenges in MSWM}

Municipal solid waste management (MSWM) has become an increasingly prominent global problem nowadays. Economic development, urbanization, and the improvement of urban living standards have increased the amount and complexity of solid waste generated (Rathi, 2007). The global annual generation of about 1.3 billion tons of solid waste in cities in 2012 is expected to finally increase to 2.2 billion tons by 2025 (Shawn Burke et al., 2018). In developing countries, solid waste management is exacerbated by higher population growth rates and lower income levels. The rapid growth rate of solid waste and improper waste disposal methods fail to address the health needs of residents and overburden the local governments (Yousif \& Scott, 2007). Waste generation rates in low-income countries will more than double over the next 20 years. Globally, the cost of solid waste management will increase from $\$ 205.4$ billion in 2012 to about $\$ 375.5$ billion in 2025 . The most significant cost increase will be in low-income countries (more than five times) and lowermiddle-income countries (more than four times) (Shawn Burke et al., 2018). This phenomenon undoubtedly poses a considerable challenge to environmental protection. An effective, efficient, and low-cost analysis of MSWM becomes very important to solve this problem, especially for low-income countries where a highly cost-effective analysis can significantly improve the analysis and solvability of the problem. Even in high-income countries, an efficient analytical approach may save expenses and accelerate development.

\subsection{Literature Selection and Screening}

This research used publications from Google Scholar to gather data on waste management concerns in Nairobi. The search was conducted with the keywords Waste Management and Nairobi in the title of the article, and the results are shown in Figure 1, with the years listed in chronological order from 1995 to 2021. During this 27-year period, the total number of qualified articles was 180 . The selection was made by finding the articles with more citations or more relevant to waste collection and use the data from the selected articles as the data source for the theoretical analysis of this paper. As shown in Figure 1, the research interest in waste management in Nairobi increases year by year, resulting in ample data support in this region.

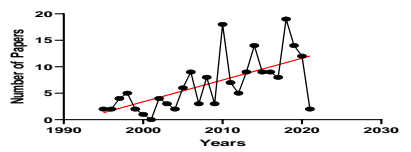

Figure 1. Number of Papers related to WM in Nairobi. (The red line is linear regression lines for the data points)

\subsection{Why is Nairobi Selected in This Case Study?}

This paper aims to demonstrate the effectiveness, high efficiency, and low cost of the Environment-based design (EBD) method in solving municipal solid waste management problems. Kenya is a typical developing country and has a lot of waste managementrelated data that can be found in the literature. Another important reason is that the analysis of a country that is irrelevant to the author's living background can better prove this method's practicability and operability. All the data used in this paper on Nairobi, Kenya, and MSWM are obtained from open-source websites and published articles. That is to say, as long as the same type of relevant data from other countries or regions is available, the EBD method can be used for integration and analysis following the same steps.

* Corresponding author 


\subsection{Why and How to Identify Critical Issues in MSWM?}

The main objective of this paper is to identify the critical problems of MSWM, which have been extensively researched and have systematic solutions in developed countries, such as Germany and Singapore, so the case study in this paper is chosen from developing countries. In addition, reducing management costs is much more critical for solid waste management in developing countries, and the cost may directly contribute to the development of MSWM. The MSWM critical issues identification of cost reduction will also provide a possibility to help solve the problem of waste management in impoverished areas. MSWM in Nairobi has been studied for over 20 years, and there are sufficient data and publications for subsequent research. This paper uses the method of EBD and Environment-based life cycle analysis (eLCA) to analyze the current situation and find critical conflicts.

\section{METHODOLOGY}

\subsection{Overview of Environment-Based Design (EBD)}

Environment-based design (EBD) is a design methodology that looks firstly at the environment in the design process (Zeng, 2011 , $2020 \mathrm{~b}$ ). The nature of design is shown by the recursive logic of design (Zeng \& Cheng, 1991). As shown in Figure 2, the EBD includes three activities, which are environment analysis, conflict identification, and solution generation, during which design problem, design knowledge, and design solutions simultaneously and interdependently evolve as a part of the environment (Yang et al., 2021). The product's environment is everything except the product itself, which can be defined in three dimensions, namely, environment types, life cycle events, and life cycle time (Zeng, 2020b).

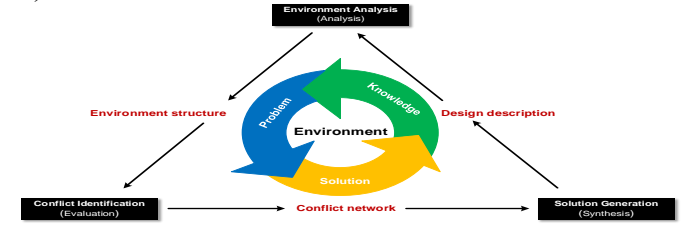

Figure 2. Environment-based design (EBD) (Yang et al., 2021).
In EBD, the sustainability-focused environment analysis method is called Environment-based life cycle analysis (eLCA) (Yang et al., 2021). EBD is a natural methodology to consider sustainability by zooming in on the sustainability critical environment since the EBD takes into account all of the environmental components relevant to a product design (Zeng, 2004, 2020b). There are four kinds of environments in eLCA, which are natural, physical artifact, digital artifact, and stakeholder (Yang et al., 2021). EBD indicates that design comes from the environment, serves the environment, and changes the environment (Zeng, 2011). Therefore, eLCA is a natural environment analysis tool to analyze the environment of a product.

\subsection{Environment Analysis}

Environment analysis is the first step in EBD, aiming to identify known environment components and their relationships between those components (Zeng, 2011). The input is the problem statement, and the output is the production environment. In the environment analysis, EBD provides two main tools, which are the Recursive Object Model (ROM) (Zeng, 2008) and question asking (Wang \& Zeng, 2009).

$\mathrm{ROM}$ is a graphic language to represent objects and their relationships for their meaning structure. EBD utilizes ROM analysis to process design problems, design knowledge, and design solutions along with the evolution of product solutions. ROM diagram consists of two types of objects and three kinds of relations, as shown in Table 1 (Zeng, 2008).

The right questions are a prerequisite for getting the right information and data. Zeng (Zeng, 2020b) had given the definition of the right question as the one asked in the right time about the right object with the right type and to the right resources. Based on the ROM diagram of a design statement, design questions can be generated using the EBD question generation template (Wang \& Zeng, 2009), as shown in Table 2. Then eLCA can be used to analyze the life cycle of a product. The answers can be generated by the guideline of answering questions (Zeng, 2020b). As a part of the detailed description of the statement, the answers will be used to update the original ROM diagram.

\begin{tabular}{|c|c|c|c|c|}
\hline Type & & & Graphic Representation & Definition \\
\hline \multirow{2}{*}{ Object } & $\begin{array}{l}\text { Primitive } \\
\text { objects }\end{array}$ & & $\overline{E_{i}^{a}}$ & Everything in the universe is an object. \\
\hline & $\begin{array}{l}\text { Object } \\
\text { structure }\end{array}$ & & $\oplus E$ & $\begin{array}{l}\text { It is an object that includes at least two other } \\
\text { objects in it. }\end{array}$ \\
\hline \multirow{4}{*}{ Relations } & Connection & & $E_{i}$ & $\begin{array}{l}\text { It is to connect two objects that do not constrain } \\
\text { each other. }\end{array}$ \\
\hline & Constraint & & 4 & $\begin{array}{l}\text { It is a descriptive, limiting, or particularizing } \\
\text { relation of one object to another. }\end{array}$ \\
\hline & \multirow[b]{2}{*}{ Predicate } & Subject-verb & $S_{i}$ & \multirow{2}{*}{$\begin{array}{l}\text { It describes an act of an object on another or that } \\
\text { describes the states of an object. }\end{array}$} \\
\hline & & $\begin{array}{l}\text { Verb/propositi } \\
\text { on-object }\end{array}$ & $v / p$ & \\
\hline
\end{tabular}

Table 1. Elements of Recursive Object Model (ROM), adapted from (Zeng, 2008).

\begin{tabular}{|l|l|l|}
\hline $\begin{array}{l}\text { Noun } \\
(\mathrm{N})\end{array}$ & Without any constraint & What/Who is N? \\
\cline { 2 - 3 } Verb & $\begin{array}{l}\text { With an adjective (A) constraint } \\
(\mathrm{O} 1)\end{array}$ & What is A? What is A N? \\
\hline Sul $)+$ Verb (V1) +Object & $\begin{array}{l}\text { What do you mean S1 V1 O1? Why do/does S1 V1 O1? When do/does S1 } \\
\text { V1 O1? } \\
\text { Where do/does S1 V1 O1? How do/does S1 V1 O1? }\end{array}$ \\
\hline
\end{tabular}

Table 2. Template for the right type of questions (Zeng, 2020b). 


\subsection{Conflict Identification}

Conflict identification is the second step in EBD, aiming to identify all potential conflicts from the updated ROM diagram using the interaction dependency network. A conflict is an insufficiency of resources for an environment object to produce a desired action on the product or to accommodate the product's response to its environment (Zeng, 2020b). Interactions are associated with verbs in a ROM diagram (Zeng, 2020b), which can be classified into the independence interaction and the dependence-only interaction (Yang et al., 2021), as shown in Figure 3. The dependence relationship between interactions forms an interaction dependency network, which can be further used to identify conflicts. Each path between the independent and dependence-only interactions defines critical issues of a problem. Examples are shown in the following case study.

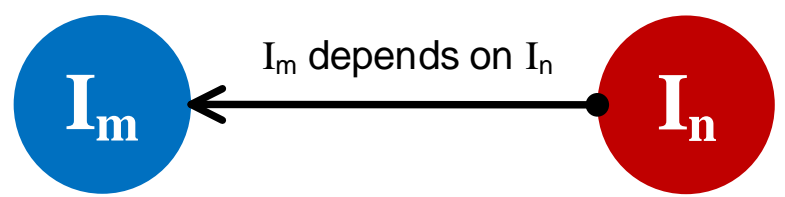

Figure 3. Dependency relation between two interactions. (Zeng, 2020a)

\section{CASE STUDY}

Nairobi, established in 1895, is the capital city, the largest city, and the main regional business center in Kenya, which is the third-largest economy in sub-Saharan Africa by 2020, second only to Nigeria and South Africa (Standard, 2020). Kenya's gross national income per capita of 1,750 USD in 2019 renders it a lowmiddle-income economy (World Bank national accounts data, 2018). The city lies in the south-central part of Kenya and covers an area of 696 square kilometers, and has a subtropical highland climate $(\mathrm{Cwb})$, with $44 \%$ of the residents live below the poverty line (Kazungu, 2010). According to the 2019 census, Nairobi's administrative region's population is $4,397,073$ (KNBS, 2019) and is growing at an annual rate of $4 \%$ to $5 \%$ due to rural-urban migration and the natural rate of increase (JICA, 1998).

It is worth mentioning that waste management is a prominent problem in Nairobi (Magutu et al., 2010). Waste management controls waste-related activities, including the collection, transport, sorting, and disposal of waste, to protect the environment and human health and to save resources (Pongrácz $\&$ Pohjola, 2004). The case study focuses on waste in the solid state, which excludes sludge from wastewater treatment and liquid chemical waste (Christensen, 2010).

\subsection{Statement Design}

According to the objective of this paper, the statement can be designed as "Manage municipal solid waste in Nairobi." According to the ROM diagram drawing method in EBD, the statement can be presented in Figure 4.

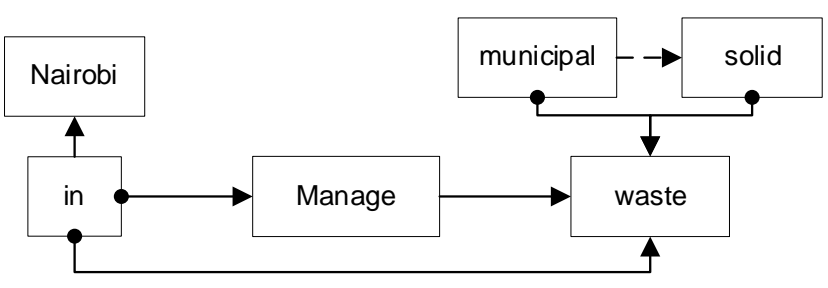

Figure 4. ROM diagram of the concept statement.

\subsection{Asking Right Questions}

\section{Questions}

Q1: What is municipal solid waste?

Q2: What is municipal solid waste in Nairobi?

Q3: Who manages the municipal solid waste in Nairobi?

Q4: Why manage municipal solid waste in Nairobi?

Q5: When to manage municipal solid waste in Nairobi?

Q6: Where to manage municipal solid waste in Nairobi?

Q7: How to manage municipal solid waste in Nairobi?

Table 3. Questions to ask based on Figure 4.

\subsection{Answering Questions: Collecting Lifecycle Information}

Life cycle analysis (LCA) of municipal solid waste (MSW) in Nairobi can be divided into LCA of products in Nairobi and LCA of municipal solid waste management (MSWM) in Nairobi. As shown in Figure 5, the LCA of products includes the extraction of natural resources, material processing, manufacturing, distribution, and use. Because the LCA of products will have different results according to the products, the results are based on commonalities in screening all the solid product's LCA. Afterward, the LCA of waste management begins, including after-use collection, sorting for re-use and recycling, and waste disposal, including composting, anaerobic digestion, landfill, and incineration. Composting can produce many agronomic benefits; energy can be recovered from the product of anaerobic digestion and the incineration process. Materials can also be recovered after combustion (Nelen et al., 2013). This paper will mainly focus on the waste collection stage in the life cycle due to the space limit.

Q1: What is municipal solid waste?

Waste is a substance or an object, which is unnecessary or unusable for the user (Rummel-Bulska \& Basavaraj-Schroth, 1994). Solid waste is waste in a solid state. Municipal Solid Waste is nonhazardous disposable materials generated by households, institutions, industries, agriculture, and sewage. It is made up of waste, organics, and recyclable materials, such as product packaging, grass clippings, furniture, clothing, bottles, food scraps, newspapers, and appliances (BUSHSYSTEMS, 2010; US EPA, 2016).

Q2: What is municipal solid waste in Nairobi?

Municipal solid waste in Nairobi is mainly organic matter, followed by plastic, paper, and others (Khamala \& Alex, 2013). The specific municipal solid waste situation of Nairobi will be detailed in the life cycle analysis (LCA).

Table 4. Answers to Questions 1 and 2 in Table 3 (Question 1 and 2 are answered first because they are the definition and basis for the subsequent questions) 


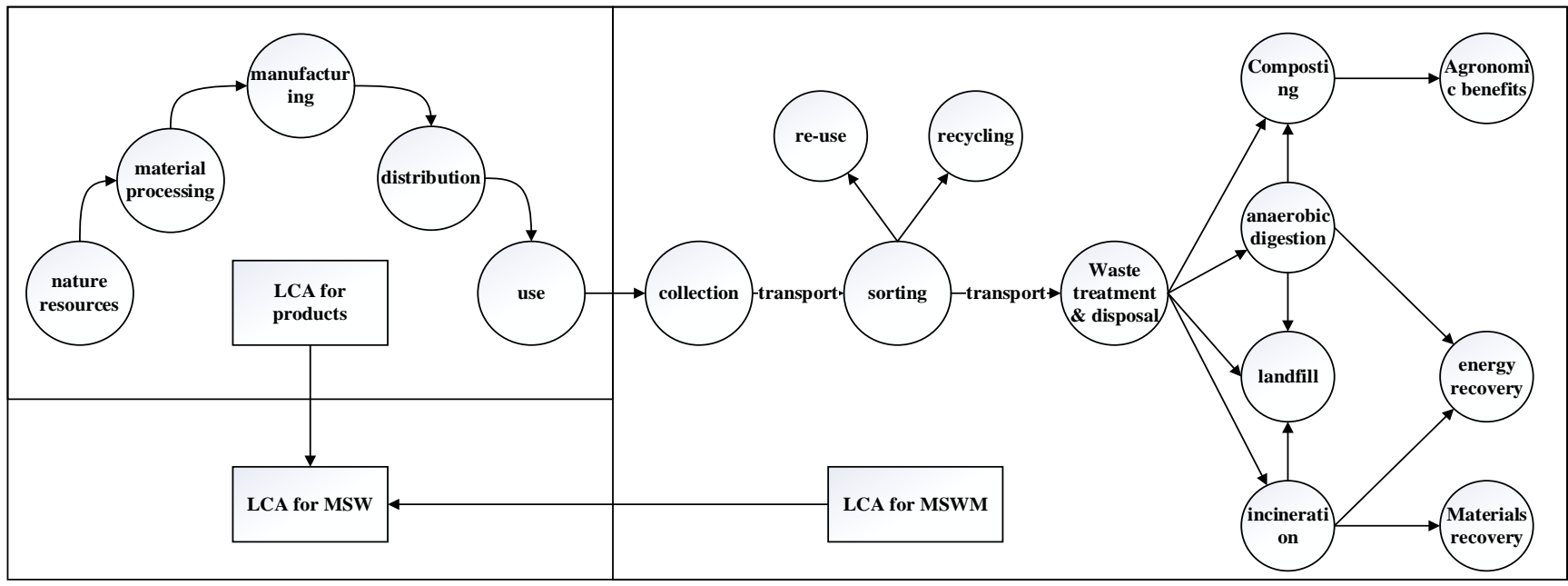

Figure 5. Components and interrelationship of municipal solid waste LCA in Nairobi.

For waste collection in Nairobi, the environmental components are:

a) The natural environment includes:

- inclement weather that may affect the waste collection,

- fossil fuels used in waste transportation vehicles.

b) The physical artifact environment includes:

- The generated waste increases rapidly in Nairobi,

- The collection rate of municipal solid waste in Nairobi is relatively low. Of the 1,530 tons of waste generated daily in Nairobi in 2002 (as shown in Table 5), the Nairobi City Council (NCC) and the private sector collect only about $25 \%$; the remaining $1,147.5$ tons is either not collected, burned, and dumped in other unauthorized places, or collected by non-governmental organizations (NGOs), community-based groups, and other groups (JICA, 1998; Kazungu, 2010),

\begin{tabular}{|c|c|}
\hline Year & Waste Generation (tonnes/day) \\
\hline 1973 & 452.66 \\
\hline 1975 & 501.92 \\
\hline 1985 & 850.86 \\
\hline 1998 & $1,426.00$ \\
\hline 2002 & $1,530.00$ \\
\hline 2004 & $2,347.00$ \\
\hline 2015 & $2,679.89$ \\
\hline
\end{tabular}

Table 5. Waste generation and change trends in Nairobi. (Source: Muniafu \& Otiato (2010) and Afdb (2002))

- The waste generation rate is proportional to the income of residents (JICA, 1998),

- The proportion of each component of total waste generated in Nairobi, as shown in Table 6. The characteristics are as follows:

1) Despite the annual decrease from 1985 to 2009 , organic waste has remained more than half of the total waste generated.

2) The rate of recyclable materials, such as paper plastic, glass, and metal, is $22.4 \%$ (JICA, 1998).

3) The total paper, plastic, glass, and metal remains unchanged at about 35\% between 1985 and 2009 .

- The uncollected waste is dumped along streets, side ditches, and other places in the city, causing hygienic, environmental, and aesthetic problems (JICA, 1998),

\begin{tabular}{|l|l|l|l|l|}
\hline \multirow{2}{*}{$\begin{array}{l}\text { Waste } \\
\text { type }\end{array}$} & \multicolumn{4}{|c|}{ Percentage Composition (\%) } \\
\cline { 2 - 5 } & 1985 & 1998 & 2004 & 2009 \\
\hline Organic & 78 & 58.2 & 61.4 & 50.9 \\
\hline Paper & 10.2 & $\begin{array}{l}17.3 \\
(14.5 \text { recyclable })\end{array}$ & 11.8 & 17.5 \\
\hline Plastic & 4.1 & $\begin{array}{l}11.8 \\
(4.7 \text { recyclable })\end{array}$ & 20.6 & 16.1 \\
\hline Glass & 3.8 & $\begin{array}{l}2.3 \\
(1.5 \text { recyclable })\end{array}$ & 0.7 & 2.0 \\
\hline Metals & 1.9 & $\begin{array}{l}2.6 \\
(1.7 \text { recyclable })\end{array}$ & 0.6 & 2.0 \\
\hline Other & 2 & 7.8 & 4.9 & 11.4 \\
\hline
\end{tabular}

Table 6. Trends in waste composition change in Nairobi. (Year refer to the time of related paper published) (Kasozi \& Von Blottnitz, 2010)

- Costs of waste collection, including mechanical, operational, and labor costs. Waste collection cost in the relatively wealthy areas of Nairobi (which occupy about $70 \%$ of the city) is less challenging because most residents living in this section are able and willing to pay for private collection companies (Muniafu \& Otiato, 2010). Meanwhile, there is no garbage collection (or only once in a few months) in the lowerincome areas, home to $70 \%$ of Nairobi's population (UN-Habitat, 2003). In these areas, waste is dumped in open spaces and accumulates into a considerable size (Frijns et al., 1997),

- Current situation of waste collection of individuals and companies. Waste collection varies significantly from region to region. The residents in lower-income areas who cannot afford private collection companies could only afford disposal on their own. On the other hand, NCC is unable to cover all the residents to provide quality services (K Njoroge et al., 2014),

- Collection operation time. As was indicated by JICA in 1998, three major private companies, i.e., Bins (Nairobi) Services Ltd., City Bins, and Domestic Refuse (K) Disposal Ltd. (usually called "DRDS"), work longer hours than NCC,

- Collection operation distance. The private collectors have a longer operating distance per trip than the NCC, approximately $35 \mathrm{~km}$ per trip for NCC and $50 \mathrm{~km}$ per trip for the private collectors (JICA, 1998),

- The number of collection trips. Due to the different collection methods as previously mentioned, the 
average number of trips per day for each collection vehicle is 1.7 to 2.0 for NCC, which is higher than the private collectors', 1.2 to 1.4 trips (JICA, 1998),

- The number of collection crew. JICA stated that the average number of crew is 4.8 for each NCC collection vehicle and 4.0 for the private collectors, respectively,

- Collection areas. According to JICA's declaration in 1998 , the proportion of NCC collecting waste from each region ranges from $14 \%$ to $23 \%$ of the total, while private collectors mostly pick up the high-income area as previously mentioned,

- The number of available collection vehicles. For NCC, the waste collection fleet size is gradually decreasing for economic or mechanical reasons, which falls far below necessary to cover the entire city (JICA, 1998).

c) The digital artifact environment includes:

- Waste collection methods. The waste collection methods can be classified into station-based and doorto-door-based collection. The station-based collection accounts for $91 \%$ for $\mathrm{NCC}$ and $48 \%$ for private collectors, while the door-to-door-based is $9 \%$ for NCC and 52\% for private collectors (JICA, 1998),

- Prediction of waste generation and residential density,

- Number and capacity of private collectors recruited by NCC. In 1998, the number of private collectors was estimated to be 60 , which can collect about $25 \%$ of the generated waste (JICA, 1998), and,

- Waste collection policy. The waste collection policy was formulated by the local government authorized by the Public Health Act and the Local Government Act, but there are some problems to be solved (JICA, 1998), e.g., the legislation is not comprehensive and the acts did not offer standards for waste collecting events.

d) The stakeholder environment includes:

- Individuals, many of whom are unaware of waste collection and have low education,

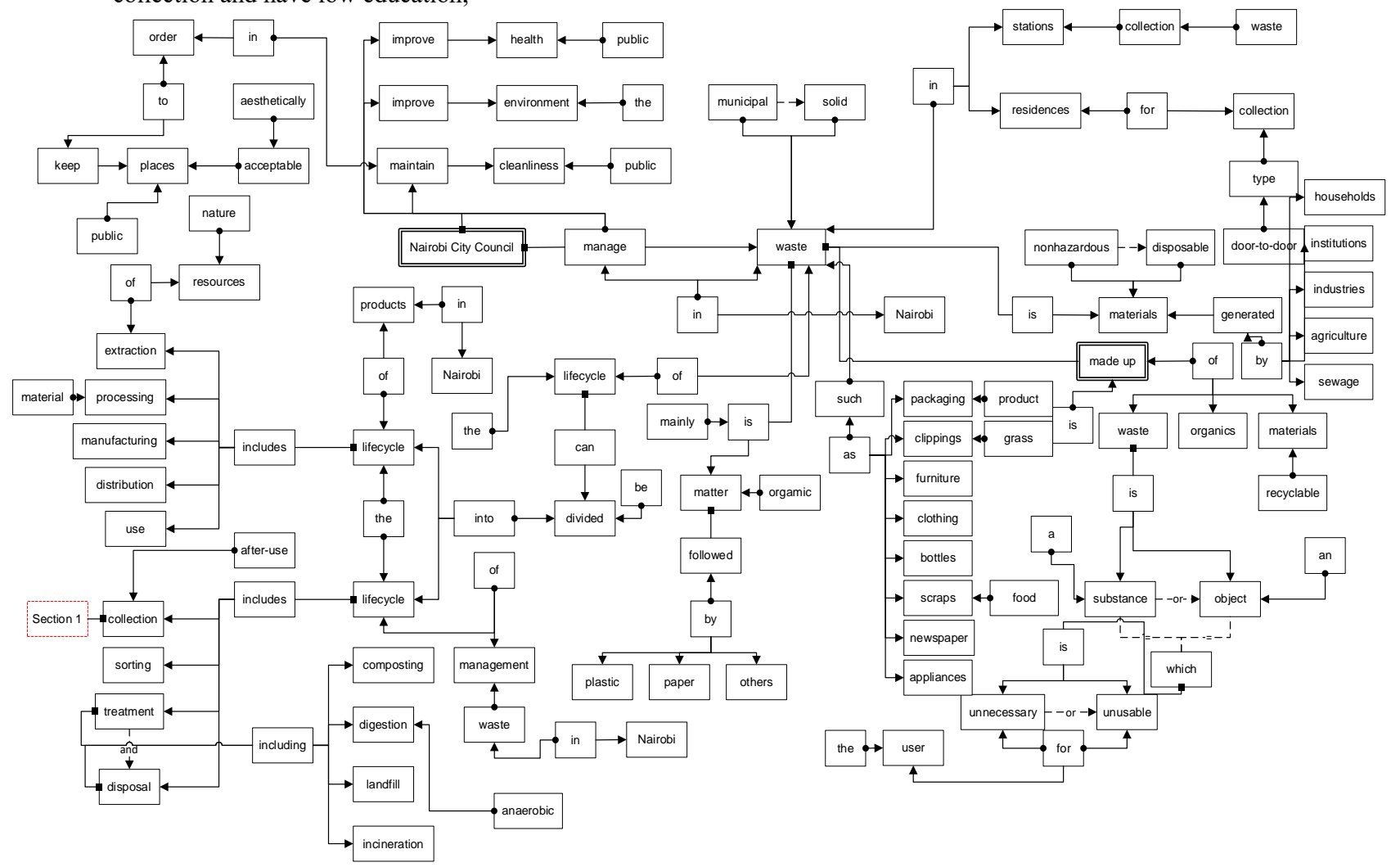

Figure 6. Updated ROM diagram.
- Private waste collection companies. They have no contractual involvement with $\mathrm{NCC}$ and are not regulated by the NCC (JICA, 1998), and

- The NCC, which is the main body responsible for providing services and managing solid waste to the city of Nairobi (K Njoroge et al., 2014).

Q3: Who manages the municipal solid waste in Nairobi?

Nairobi City Council (NCC).

Q4: Why manage municipal solid waste in Nairobi? cleanliness to keep public places aesthetically acceptable (Magutu et al., 2010)

Q5: When to manage municipal solid waste in Nairobi?

Municipal solid waste management occurs at every stage of the LCA of MSWM (as shown in Figure 5). This paper mainly focuses on manage the MSW in the waste collection stage.

Q6: Where to manage municipal solid waste in Nairobi?

As we mainly focus on the waste collection stage, NCC manages MSW in waste collection stations and residences for door-todoor-based collection (JICA, 1998).

Q7: How to manage municipal solid waste in Nairobi?

Solid waste management problems in Nairobi mainly result from the lack of a waste management policy framework to guide the improvement of standards, efficiency, and coverage of waste management (Magutu et al., 2010). This problem can serve as the direction for later researchers to study.

Table 7: Answers to the questions in Table 3.

\subsection{Updated ROM Diagram}

Figures 6 and 7 show the updated ROM diagram after merging the answers and the environmental components of waste collection.
To improve public health and the environment, maintain public 


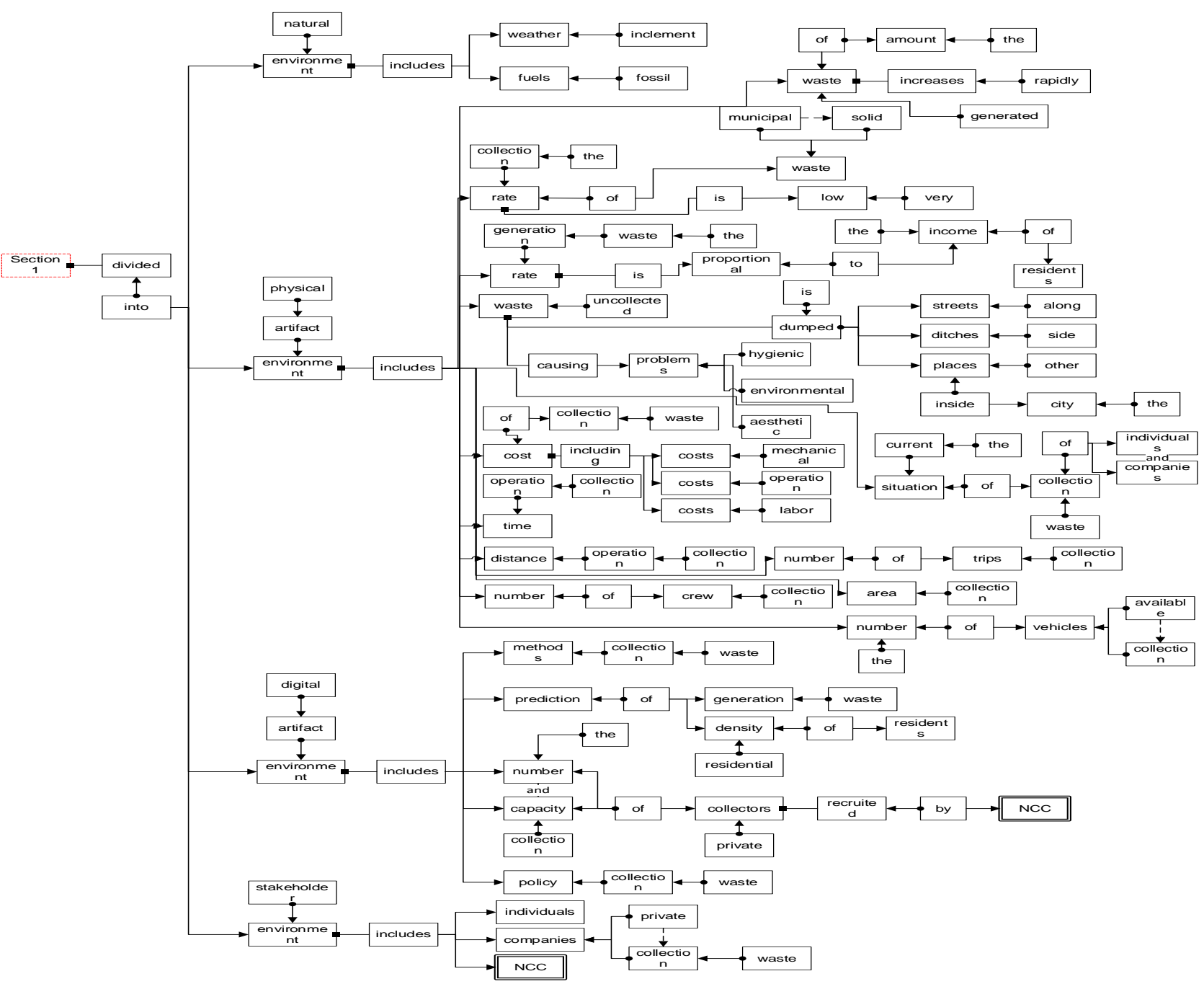

Figure 7. Section 1 (waste collection) of Figure 6 ROM diagram.

\subsection{Modeling Dependency}

To identify the critical issues, we need to find explicit and implicit interactions from the updated ROM diagram. The interactions from Figures 6 and 7 are listed in Table 8.

\begin{tabular}{|c|l|c|}
\hline Interaction & Description & Dependence \\
\hline I1 & NCC manages the municipal solid waste in Nairobi. & I1 \\
\hline I2 & NCC improves public health. & I1 \\
\hline I3 & NCC improves the environment. & I1 \\
\hline I4 & NCC maintains public cleanliness. & I1, I4 \\
\hline I5 & NCC keeps public places aesthetically acceptable. & I8 \\
\hline I6 & Municipal solid waste collected in stations. & I \\
\hline I7 & Municipal solid waste collected door-to-door in residences. & \\
\hline I8 & Households, institutions, industries, agriculture, and sewage generate municipal solid waste. & I12, I14 \\
\hline I9 & Waste, organics, and recyclable materials make up municipal solid waste. & I9 \\
\hline I10 & NCC collects a low rate of municipal solid waste. & $\mathrm{I} 6, \mathrm{I} 7$ \\
\hline I11 & The waste generation rate proport to the income of residents. & $\mathrm{I} 10, \mathrm{I} 14, \mathrm{I} 15, \mathrm{I} 16$ \\
\hline I12 & The cost of waste collection, including mechanical, operation, and labor costs. & $\mathrm{I} 8, \mathrm{I} 11$ \\
\hline I13 & Individuals and companies collect waste. & $\mathrm{I} 10$ \\
\hline I14 & Waste increases rapidly. & $\mathrm{I} 15$ \\
\hline I15 & Uncollected waste dump along streets, side ditches, and other places inside the city. & $\mathrm{I} 1, \mathrm{I} 2, \mathrm{I} 3, \mathrm{I} 4, \mathrm{I} 10$ \\
\hline I16 & Uncollected waste causes hygienic, environmental, and aesthetic problems. \\
\hline I17 & NCC recruit private collectors. & \\
\hline
\end{tabular}

Table 8. Interactions for manage MSW in Nairobi.

After finding the interactions, we construct the interaction dependency network in Figure 8 based on the dependences. 


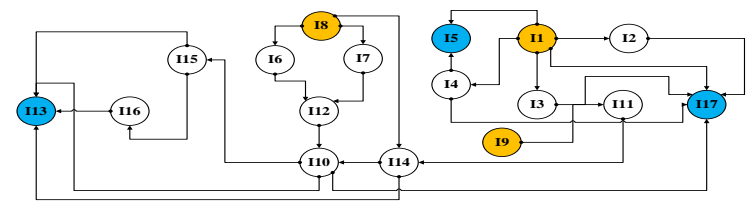

Figure 8. The interaction dependency network, with independent (yellow) and dependency-only (blue) interactions. Figure 9 is simplified from Figure 8 by removing the dependence between the two interactions if they have longer dependencies.

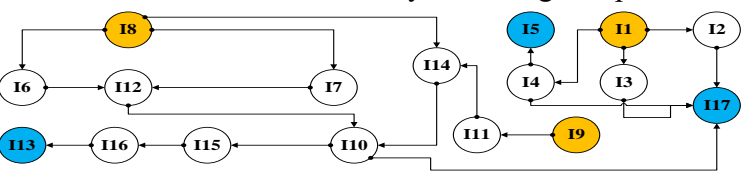

Figure 9. Simplified interaction dependency network. All the potential paths from Figure 9 are shown in Figure 10.

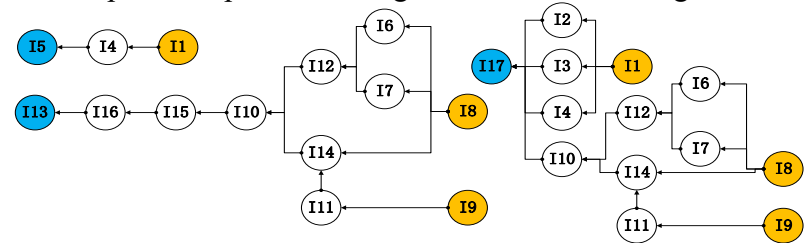

Figure 10. Paths in simplified interaction dependency network.

\subsection{Case Study Results}

This case identified three critical issues (in blue) in Figure 10.

- $\quad$ I5: NCC keeps public places aesthetically acceptable.

- I13: Individuals and companies collect waste.

- I17: NCC recruits private collectors.

Magutu et al. (2010) collected data from fifty members and managers of the Nairobi City Council and analyzed it using descriptive statistics, then aggregated the data and presented it in the form of proportions, tables, and percentages. As a result, identified the critical municipal solid waste management issues include poor services for solid waste collection and large amounts of uncollected solid waste. This result is very similar to the critical issues I5. Also, in the report published by Japan International Cooperation Agency (JICA) in 2010, a team of expert researchers conducted a year-long study from October 2009 to October 2010. One of the critical problems is uncontrolled private sector involvement in waste collection services (JICA, 2010), equivalent to the consolidation of I13 and I17. This result proves that the critical issues we have identified are, to some extent, consistent with published literature.

In general, the approach proposed in this paper differs from Magutu and JICA in that EBD emphasizes identifying the main problems of waste management from design, whereas these two articles and most of the published articles on waste management issues uncover the fundamental problems mainly from the user or resident feedback. In addition, the EBD approach requires less experience and resources, and unlike traditional questionnaire or walk-in survey methods, starting from the perspective of the waste management problem itself rather than relying on large amounts of feedback data may offer new possibilities for better solutions to the waste management problem.

ROM diagram shows the components included in the environment system and the relations between the components. The ROM analysis process allows for a more objective understanding by transforming the original design problem statement described by natural language into a ROM diagram. ROM analysis is methodology oriented while experts are primarily experience-based (Zeng, 2020b). As the time and labor cost of this method may affect its feasibility to some extent, we measure the time taken to learn the method, collect data, apply the method, draw ROM diagrams, and conduct subsequent analyses by a master's student with no experience in waste management-related research. The result is shown in Table 9.

\begin{tabular}{|l|l|}
\hline Step names & Time statistics \\
\hline EBD theory study & $32 \mathrm{~h}$ \\
\hline Data Search & $53 \mathrm{~h}$ \\
\hline Draw ROM diagram and analyze & $35 \mathrm{~h}$ \\
\hline Total & $120 \mathrm{~h}$ \\
\hline
\end{tabular}

Table 9. Case study step-by-step time statistics

\section{DISCUSSION}

To reduce the environmental impact of solid waste and decrease management costs, improving the availability of solid waste management to relatively emerging countries, EBD can be used to analyze the whole life cycle of the object in the statement, such as waste life cycle or waste management life cycle, for an extremely low cost. The case study results can demonstrate the effectiveness of the EBD approach, while the authors, who had no contact with the local environment, used open-source information to analyze the critical issues at a breakneck pace can demonstrate the efficiency of the approach.

However, this paper also has the following limitations to note. First, since the paper is based on a statement, an insufficient coverage of the statement may lead to inadequate conclusions. Second, the completeness of life cycle information collection is crucial; incomplete collection may lead to the omission of certain essential information and thus missing results. Third, practical operation and understanding of the EBD method require specialized study; creation and reading of ROM diagrams likewise require dozens of hours before one can properly draw and understand these diagrams. Improving readability and usability of ROM diagrams for non-experts will be desirable in subsequent studies. Finally, some of the data used in this paper are somewhat old, but since there is no more suitable new data, the analysis was conducted using part of the old data. Comparison of the results of the analysis with that in the 2010 studies by Magutu and JICA (the peak year for the number of research publication on waste management in the Nairobi region, as shown in Figure 1) can verify both validity and feasibility of the method, and minimize the impact brought by part of the outdated data.

\section{CONCLUSION}

The analysis of municipal solid waste management problems in Nairobi has shown that the EBD method is feasible and applicable in finding the key issues, helping designers find the relationship between the issues, and make the next step plan. In this paper, the EBD method is used for the first time to identify the critical issues of MSWM, using the city of Nairobi as a case study. It took us about 120 hours with no knowledge of the city at all to complete the analysis of the critical issues in Nairobi, and the results are proven to be reliable. This is sufficient evidence that EBD can be more efficient and effective compared to the traditional expert brainstorming. The key to EBD in finding the critical issues is to consider the environment first rather than the problem itself as designers usually do, which may make researchers uncomfortable. Future research will consider how to make the method more designer-friendly. In addition to the case of Nairobi, the EBD method will also be used in other cities for further demonstration and validation.

\section{ACKNOWLEDGMENT}

This project is partially supported by Fonds Québecois de la Recherche sur la Societe et la Culture. 


\section{REFERENCES}

BUSHSYSTEMS, 2010. What Is Municipal Solid Waste (Msw)? https://www.buschsystems.com/resource-center/

knowledgeBase/glossary/what-is-municipal-solid-waste-msw

Christensen, T. H., 2010. Solid Waste Technology \& Management. Blackwell Publishing Ltd., Chichester, UK.

Damgaard, A., \& Barlaz, M. A., (n.d.). The Application of LifeCycle Analysis to Waste Management. NC State University.

Frijns, J., Kirai, P., Malombe, J., and V. B., 1997. Pollution Control of Small-scale Metal Industries in Nairobi.

JICA, 1998. The Study of Solid Waste Management in Nairobi City, Final Report.

JICA, 2010. Office of the Deputy Prime Minister Ministry of Local Government Republic of Kenya City Council of Nairobi Preparatory Survey for Integrated Solid Waste Management in Nairobi City in the Republic of Kenya. 4(October), 1-69.

K Njoroge, B. N., Kimani, M., \& Ndunge, D., 2014. Review of Municipal Solid Waste Management: A Case Study of Nairobi. In Research Inventy: International Journal Of Engineering And Science, 4(2).

Kasozi, A., \& Von Blottnitz, H., 2010. Solid Waste Management in Nairobi: A Situation Analysis Technical Document accompanying the Integrated Solid Waste Management Plan. Environmental \& Process Systems Engineering Group, 9-12

Kazungu, R. K., 2010. Improving Governance for Sustainable Waste Management in Nairobi. 46th ISOCARP Congress, 1-8.

Khamala, E. M., \& Alex, A. A., 2013. Municipal Solid Waste Composition and Characteristics Relevant To the Waste - ToEnergy Disposal Method for Nairobi City. 2(4), 1-6.

KNBS, 2019. 2019 Kenya Population and Housing Census Volume 1: Population by County and Sub-County.

Magutu, P. O., Mbeche Prof., I. M., Nyamwange, O., Mwove Ms., M. N., Ndubai, R. E., \& Nyaanga, R. O., 2010. Formulation and implementation of operation strategies used in solid waste management: Case study of Nairobi city council. Proceedings of the 12th International Business Information Management Association Conference, IBIMA 2009, 1-3, 265-281.

Muniafu, M., \& Otiato, E., 2010. Solid Waste Management in Nairobi, Kenya. A case for emerging economies. Journal of Language, Technology \& Entrepreneurship in Africa, 2(1), 342350 .

Nelen, D., Van Der Linden, A., Vanderreydt, I., \& Vrancken, K., 2013. Life cycle thinking as a decision tool for waste management policy. Revue de Metallurgie. Cahiers D'Informations Techniques, 110(1), 17-28.

Palczynski, R. J., 2002. Study On Solid Waste Management Options For Africa by African Development Bank. Journal for Applied Research, 2(7), 131-567.

Pongrácz, E., \& Pohjola, V. J., 2004. Re-defining waste, the concept of ownership and the role of waste management. Resources, Conservation and Recycling, 40, 141-153.
Rathi, S.,2007. Optimization model for integrated municipal solid waste management in Mumbai, India. Environment and Development Economics, 12(1), 105-121.

Rummel-Bulska, I., \& Basavaraj-Schroth, 1994. The Basel Convention on the Control of Transboundary Movements of Hazardous Wastes and their Disposal. In Central European Journal of Public Health, 2(SUPPL).

Shawn Burke, C., Salas, E., Smith-Jentsch, K., \& Rosen, M. A., 2018. Measuring Macrocognition in Teams: Some Insights for Navigating the Complexities. In Macrocognition Metrics and Scenarios (pp. 29-44). CRC Press.

Standard, 2020. Kenya now third-largest economy in subSaharan Africa - The Standard.

UN-Habitat, 2003. The Challenge of Slums - Global Report on Human Settlements.

US EPA, 2016. Municipal Solid Waste. https://archive.epa.gov/epawaste/nonhaz/municipal/web/html/

Wang, M., \& Zeng, Y., 2009. Asking the right questions to elicit product requirements. International Journal of Computer Integrated Manufacturing, 22(4), 283-298.

World Bank national accounts data and O. N. A. data files., 2018. GNI per capita, Atlas method (current US\$). https://data.worldbank.org/indicator/NY.GNP.PCAP.CD

Yang, J., Zeng, Y., Ekwaro-Osire, S., Nispel, A., \& Ge, H., 2021. Environment-based life cycle analysis (eLCA): integration of product usefulness and environment sustainability. 0, 4-11.

Zeng, Y., 2011. Environment-Based Design (EBD). Proceedings of the ASME 2011 International Design Engineering Technical Conferences \& Computers and Information in Engineering Conference, IDETC/CIE 2011, 1-14.

Yousif, D. F., \& Scott, S., 2007. Governing solid waste management in Mazatenango, Guatemala: Problems and prospects. In International Development Planning Review, 29(4).

Zeng, Y., \& Cheng, G. D., 1991. On the logic of design. Design Studies, 12(3), 137-141.

Zeng, Y., 2004. Environment-based formulation of design problem. Journal of Integrated Design and Process Science, 8(4), $45-63$.

Zeng, Y., 2008. Recursive object model (ROM)-Modelling of linguistic information in engineering design. Computers in Industry, 59(6), 612-625.

Zeng, Y., 2015. Environment-based Design (EBD): A methodology for transdisciplinary design. Journal of Integrated Design and Process Science, 19(1), 5-24.

Zeng, Y., 2020a. Conflict: The Driver for a Conceptual Design. In Design Lab, CIISE, Concordia University, Canada.

Zeng, Y., 2020b. Environment: The First Thing to Look at in Conceptual Design. Journal of Integrated Design and Process Science, 1-25. 